\title{
Marketing and Future of Mobile Audio Apps - case study of the Ximalaya FM
}

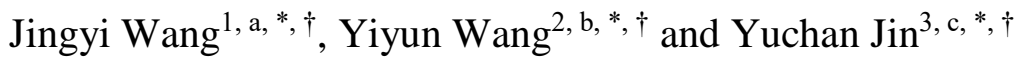 \\ ${ }^{1}$ Xiamen University Malaysia, Sepang, Selangor, 43900, Malaysia \\ ${ }^{2}$ Tianyi High School, Wuxi, Jiangsu 214000, China \\ ${ }^{3}$ Xi'an Gaoxin NO.1 High School International Course Center, Xi'an, Shaanxi, 710075, China

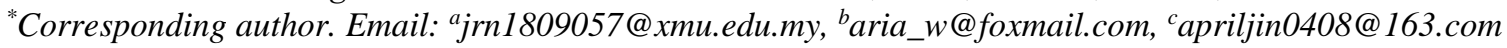 \\ These authors contributed equally.
}

\begin{abstract}
This paper aims to study some characteristics of mobile audio APP in the mobile audio market and intends to analyze the market situation based on specific cases. The importance of this article to the media sector is that it can provide a partial reference for the marketing strategy of mobile audio apps. We have mainly used the analysis of Ximalaya FM company through the use of various online professional materials and academic papers as an example to reflect the marketing strategies and business models of the mobile audio industry and to further reflect on the differences between the business models of audio companies by comparison with those of Litchi and Dragonfly FM. We found that Xiamalaya FM becomes the top of the mobile audio industry by using its rich platform content, a combination of free and paid content, and accurate 4Ps marketing strategies. Therefore, the general pricing rule for the audio industry is to offer course-level pricing by studying different consumer groups and then adding various promotions and advertisements. Therefore, the results of this study tend to be specific to a case, but there are relatively general findings in this media field. Different audio stations should accept the general phenomenon of the market and adopt different marketing strategies and pricing according to their own business models to be successful.
\end{abstract}

Keywords: Mobile audio, Marketing strategies, PUGC, Ximalaya FM, 4P framework

\section{INTRODUCTION}

With the development of technology and the application of new media, Internet radio has emerged as time requires. Mobile audio stations rely on their high interactivity, civilianization, liberalization, and other characteristics to enable audiobooks to develop rapidly relying on mobile stations. At present, the development of mobile audio platforms has begun to take shape. As a new form of media, the Internet radio APP contains a huge commercial value.

The development of audiobooks is inseparable from the boost of the macro environment. The development of the economy has increased users' demand for entertainment, so the mobile audio market for audiobooks has begun to receive people's attention. Since 2015, China's mobile radio market has gradually entered a period of rapid development. As of 2018, the number of China Mobile Radio users has reached 298 million and is expected to reach 385 million by the end of 2020 [1]. The number of active audio players in China Mobile is increasing year by year.

In addition, with the rapid development of mobile devices, digital technology has changed the way knowledge is spread. Through mobile audio platforms like Ximalaya, audiences are no longer passively accepting knowledge. They can participate in the entire dissemination process and interact with the spreaders of knowledge. Therefore, this method of knowledge dissemination has also been widely accepted.

In March 2013, the Ximalaya radio mobile client was launched. Many studies have explored the content production method of mobile audio because of the evolution from traditional broadcasting to network broadcasting. According to a literature review, the content production of mobile audio has evolved from Professional Generated Content (PGC) to User Generated Content (UGC) [2]. For example, Ximalaya FM has innovated the content production model into a Professional User Generated Content (PUGC) model, 
combining UGC and PGC, allowing users to become content producers [3]. The emerging manifestations of mobile stations such as Ximalaya have greatly affected the traditional broadcast media market.

The second section illustrates the background of audio industry development. The results and Discussion section will present the findings based on the case study analysis. To be specific, we will analyze the marketing strategy of Ximalaya FM from the perspectives of Product, Price, Place, and Promotion. At the same time, this paper will also analyze the Business model of Ximalaya FM. Moreover, the economic conditions of Ximalaya FM and its main competitors in the mobile audio market will be discussed. This study aims to take Ximalaya FM as an example to reflect the characteristics, development status, and industry prospects of marketing strategies used in mobile audio applications. Therefore, the important reference significance of this study is that its analysis can provide relevant strategies for the future development of some mobile audio applications.

\section{BACKGROUND OF DEVELOPMENT OF THE AUDIO INDUSTRY IN CHINA}

China's mobile audio market entered the exploratory stage as early as 2010. In November 2009, Douban TM was officially launched, and China's audio market started the radio mode. From 2010 to 2012, mobile stations such as Dragonfly FM were established one after another, and Ximalaya FM and Koala FM were launched one after another [4]. Starting in 2010, traditional broadcast content began to migrate. The mobile audio market was in the initial stage of market development from 2013 to 2014. The result of the initial development was that the mobile audio market developed rapidly from 2015 to 2017, and the number of users exceeded 100 million. During the period 2016-2019, the size of my country's Internet audio market has shown an overall growth trend year by year [4]. The growth rate has slowed down in the past two years, but it is still growing rapidly. In 2019, China's Internet audio market scale was 8.772 billion yuan, a year-on-year increase of $56.50 \%$. Audio entertainment, content payment, and advertising and marketing accounted for $95 \%$ of the total market scale [1]. Auditory entertainment accounted for $40 \%$ of the total market size, followed by content payment, which accounted for $34 \%$ of the total market size; advertising marketing accounted for $21 \%$ of the total market size [1].

From the perspective of the development of China's mobile audio market, the market environment provides certain conditions for the development of mobile audio platforms. From a political point of view, national policies have promoted the development of the industry. In 2013, the Ministry of Culture issued the "Administrative Measures for the Content Selfexamination of Online Cultural Business Units" at the policy level. In 2015, the State Administration of Press,
Publication, Radio, Film, and Television promulgated the Administrative Measures for the Dissemination of Audiovisual Programs on the Internet and Other Information [5]. From 2016 to 2017, measures such as the Opinions on Improving the Property Rights Protection System to Protect Property Rights in accordance with the Law have been successively introduced, which have further regulated the mobile audio market environment [5]. At the same time, the National Copyright Administration has launched a special action to combat Internet infringement and piracy, focusing on rectifying the sharing of knowledge sharing on webcasting. It has also strengthened the supervision and regulation of audio content [4].

From an economic point of view, the application and deepening of China's "Internet +" strategy has encouraged the development of mobile audio. "Internet + " is the combination of the Internet and traditional industries, using the development of science and technology to integrate the Internet with traditional industries and using the advantages and characteristics of the Internet to develop traditional industries [4]. Economically, mobile audio has been encouraged by the "Internet +", and has gained an economic foundation to innovate in the digital cultural industry, thereby cultivating innovative companies.

From a social perspective, the multi-faceted, multilevel, and diversified spiritual and cultural needs of users also drive the development of the cultural industry. Mobile audio meets the needs of users for fragmentation and convenience. At the same time, at this stage, users have a strong demand for various forms of audio content such as novels, humanities, and so on, and there are huge development opportunities.

\section{RESULT AND DISCUSSION}

\subsection{An Overview of Ximalaya Company}

Ximalaya FM was founded in 2018, and the platform is dedicated to audio sharing. As a professional audio sharing platform, it brings together hundreds of millions of audios related to audiobooks, cross talks, news, etc. Close to Spotify's operating model, the platform combines free content and pays content to better increase the number of customers. Since the launch of the mobile client in 2013, the total user scale has exceeded 600 million, making it one of the largest and fastest-growing mobile audio companies in China [6]. With regard to the current development of the audio industry, the "Ximalaya FM", "Litchi" and "Dragonfly FM" mobile audio platforms are currently the three largest mobile audio application platforms in my country [7]. In the following section, we would present the marketing model analysis of Ximalaya FM based on the 4P framework, the business model analysis of Ximalaya FM, and the analysis of its main competitors. 


\subsection{Marketing model analysis of Ximalaya FM based on the $4 P$ framework}

The product, price, place, and promotion of a good or service (4 P) of marketing are the key factors involved in the marketing of a good or service. Often referred to as the marketing mix, the four Ps are constrained by internal and external factors in the overall business environment, and they interact significantly with one another [8]. The concept of the four Ps has been around since the 1950s; as the marketing industry has evolved, the concepts of people, process, and physical evidence have become important components of marketing a product, too [8].

\subsubsection{Product}

Product refers to a good or service that a company offers to customers. Ideally, a product should fulfill an existing consumer demand [9]. The most direct product for the Ximalaya Company is the Ximalaya FM application, which includes more than 6 million audio products for listening courses, divided into two main parts. The first part is a free channel, including five parts: talking books, entertainment, knowledge, life, and radio features [9]. The second part is the live audio programs, mainly composed of the following three types, the transmission of traditional radio stations, famous brand presence, and the influential self-media knowledge stars. Firstly, many traditional radio stations on the platform, such as Xi'an Radio Station and Beijing Radio and Television University, share various traditional local cultures and report on local news. Secondly, in the application of Ximalaya, there are many famous brands at home and abroad. Examples include the proliferation of news, tesla motors, and Chinese central television. These brands share information about their companies and products on the platform. Thirdly, many Chinese stars have their own personal radio stations on the Ximalaya platform, such as Guo Degang, a famous comedian, and Luo Xiang, who teaches legal knowledge. The stars share their personal experiences, impart their knowledge and resonate with the audience on the platform.

\subsubsection{Price}

Price is the cost consumers pay for a product [8]. Customers pay 1RMB for the service with the Ximalaya FM broadcasting currency, "happy point" [9]. At present, the company mainly adopts differential pricing and psychological pricing. The Ximalaya includes six courses in addition to the 18RMB VIP course. Among those courses, master courses, quality courses, and excellent books analysis value $99-200 \mathrm{RMB}$; mini-class is worth 9.9-19.9 RMB; training battalion values 298998RMB, which is mostly provided for college students [9].

\subsubsection{Place}

When a company makes decisions regarding place, they are trying to determine where they should sell a product and deliver the product to the market [8]. Ximalaya combines online and offline marketing channels to sell its products. On the one hand, the online application provides software and program output. On the other hand, the company cooperates offline with hardware merchants, and the product has been used in many areas such as smart homes, cars, audio, and so on [10]. Besides, Rokiddy recently teamed up with Ximalaya to create a vehicle-mounted voice assistant.

\subsubsection{Promotion}

Promotion includes advertising, public relations, and promotional strategy [8]. Ximalaya company mainly adopts the model of advertising profit and sector economic profit [11]. As for advertising revenue, Ximalaya primarily uses advertisers to deliver ad programs that match the location, content, and style of ads and programs as much as possible, adapting ads into segments that greatly enhance user experience [11]. On the other hand, the company uses different forms of consumer festivals to boost consumption. The most typical festival is the country's first content consumption festival, "123 Knowledge Carnival" [10]. The total revenue of the festival reached 7.75 million dollars in 2015 and 30 million dollars in 2017 [10].

\subsection{Business Model Analysis of Ximalaya FM}

The business model refers to the company's core strategy for profitably doing its business. To emphasize the Reidy business model of Ximalaya, one of the representative companies in the audio industry, the following content will mainly analyze the main products, operating mode, and revenue resources of the Ximalaya FM company.

\subsubsection{The Professional User Generated Content system}

Professional User Generated Content (PUGC) refers to professional video content produced in UGC, which is relatively close to PGC content [12]. The PUGC system combines both the professionalism and high reputation of PGC programs with the breadth and diversity of UGC programs.

As a large-scale audio platform with more than 10 million, UGC content is an important factor for the Ximalaya FM platform to have such a large content and breadth. The Ximalaya FM platform strongly encourages users to upload homemade audio spontaneously: the official website has an upload interface in the APP interface. At the same time, Ximalaya FM provides a voice recording function with low operating difficulty 
[13]. In order to effectively improve audio quality, Ximalaya FM has added a big "V" certification system and set up an anchor training program. Besides, Ximalaya FM has opened a series of anchor training courses to cultivate the professionalism of anchors [14].

While introducing traditional resources such as various programs of national, provincial, and municipal channels, local channels, and network channels to create PGC resources, Ximalaya FM also focuses on boutique self-made programs produced by a professional team, cooperating with high-profile celebrities, like a famous writer, cross talk actor and famous TV host. Ximalaya also took advantage of the popular drama "Strategy of Yanxi Palace" in the summer of 2018 and cooperated with Oushiman to create a customized IP, "The Wisdom of Life of Queen Fucha". It effectively interprets the brand connotation of OSM and attracts brand audience users, achieving good promotion effects and improving at the same time Brand image and transfer brand value [15].

\subsubsection{Revenue Resources}

Revenue resources of Ximalaya FM can be roughly divided into three categories: advertising profit, fan economic profit, and smart hardware profit.

Advertising revenue is the main source of income for audio platforms and audio players. Ximalaya FM provides a large number of advertising spaces in the software interface, such as app start-up ads, focus map ads, play page ads, and audio ads, and open advertising investment. The platform uses big data to accurately place advertisements when used by non-member users and increase the effective delivery rate to achieve profitability. Another advertising revenue comes from the ad naming of self-made premium content. For example, the Ximalaya FM self-produced program "Duanzi Laile" has been broadcasted 630,000 times in a single period, and it has won millions of advertisers' annual titles [16].

The fan economic model of Ximalaya FM can be divided into two modes: member recharge and single premium audio recharge. Ximalaya FM maintains a large number of users with free resources and then uses premium products to attract users to subscribe and pay. In 2016, Ximalaya FM took the lead in launching the single audio payment business, and such content consumption has become the new favourite of young people [17].

Focusing on functional hardware such as mobile phones and in-vehicles, Ximalaya FM has cooperated with Baidu, Xiaomi, Huawei, and many other companies to integrate audio content into users' lives. It also independently developed "On-the-Car Audio," "smart fairy tale machines," "Tingshubao", etc. Physical products, aimed at car owners, children, and other target groups. In 2015, Ximalaya FM and Didi announced cooperation [18]. Didi car owners will have the opportunity to obtain "On-the-Car Audio", in-vehicle intelligent hardware [18].

In $2019,36.1 \%$ of business revenue came from advertising sales, $40.84 \%$ came from the fan payment business, and $22.95 \%$ came from smart hardware [19]. With the increase in users, its revenue increased fan payment business and declined in advertising sales. Ximalaya FM's gross profit margin is expected to continue to decline slowly and stabilize.

\subsection{Competitor Analysis}

This section will analyze and compare the two main Ximalaya competitors, Litchi and Dragonfly FM, to reflect the main operating models of contemporary Chinese audio industry companies. Up to March 2020, China' s mobile audio active user scale ranked high mainly for Ximalaya, Dragonfly FM, Litchi. The active users scale is more than 20 million people, of which the size of the active Ximalaya users 86.61 million, higher than the other [20].

Litchi mainly uses the UGC model to display their original content via an internet platform or make it available to other users [21]. The company initially introduced 500 anchor people who could create quality products of their own. Through the guidance and planning of professionals and the dissemination of follow-up programs, more and more listeners learned, participated, and finally transformed into anchor [22].

Dragonfly FM uses the PGC business model. PGC program is produced almost in the same way as television programs by traditional broadcasters. Still, it must be adjusted according to the transmission characteristics of the Internet the content dissemination level [23]. Focusing on the quality of the anchor and resources, the company worked with a number of traditional radio stations and quality classics to deliver the most effective knowledge outputs to users.

\section{CONCLUSION}

As one of the most popular mobile Internet markets currently, the industry of mobile radio is booming. With the deepening of the "Internet + " information strategy, audio moves from the small crowd to the public. The mobile radio APP represented by Ximalaya Radio leads the mobile radio industry to carry out in-depth commercial development step by step. Under the background of various advantages such as the development of Internet technology, the upgrading of public consumption, and the support of macro policies, Ximalaya Radio has developed its unique marketing mode, enabling this mobile radio App to develop a very large scale in a short period. 
From the previous analysis of the Ximalaya FM marketing model, its products are priced flexibly, adjusting prices according to different consumption levels and course quality. Also, Ximalaya owns two channels of marketing means, online and offline marketing. As for online marketing, the company mostly depends on the sale of different courses and content consumption festival, 123 Knowledge Carnival. From the previous business model analysis of Ximalaya FM, it could be found that the main reason that why Ximalaya can become one of the largest companies in the audio market is its rich platform content and its combination of free and paid content, which attacked a large number of users. Through professional PGC, PUGC content guarantees the depth of content production and creates an all-round audio industry chain. The original single content payment model realizes precise marketing, in conjunction with self-developed audio products, realizes the growth of user consumption profits.

The discovery of Ximalaya marketing strategies reflects in part the general pricing rules for audio application companies: offering course-level pricing by studying different consumer groups and then adding various promotions and advertisements. To maintain a certain advantage in a competitive market, it must maintain a high-quantity level of content production. To be more specific, Ximalaya FM needs to strengthen product innovation after the promotion reaches the goal, attracting enough users and strengthening and improving user feedback mechanism. In this way, the platform's reputation can be effectively improved, and customer viscosity can be increased.

In the future, the situation of "ear economy" is very considerable, and mobile radio will soon usher in many opportunities. There is no denying that the future of mobile audio platforms is full of many unknowns. On the one hand, the development of Ximalaya Radio is still in the stage of exploration and improvement, and there will be more difficulties and challenges in the future. The practicability of Ximalaya FM's business strategy still depends on time and the market.

However, the case study makes a detailed analysis of Ximalaya FM's business model and studies Ximalaya FM with the 4P framework. It reflects that in the mobile audio application market, the mobile audio application system is based on UGC and PGC and has the characteristics of PUGC system. At the same time, advertising revenue is the main revenue source of the audio platform. Therefore, the case study helps the employees of mobile audio applications pay attention to the communication characteristics and content communication level of their own platform system and pay attention to the focus of platform revenue. Besides, it provides value for researchers to better understand the characteristics of today's popular mobile audio stations.

\section{REFERENCES}

[1] Foresight Economists. Analysis of China Mobile Audio Industry Market Status and Development Prospect in 2020. [Online] 2020, Retrieved on April 5, 2021, from:

https://baijiahao.baidu.com/s?id=16670079297867 $49065 \& w f r=$ spider $\&$ for $=p c$

[2] Krumm, J. Davies, N. Narayanaswami, C. "UserGenerated Content". IEEE Pervasive Computing. 7 (4) (2008): 10-11. DOI:10.1109/MPRV.2008.85. ISSN $1558-2590$

[3] Feng, F. Internet radio content production under PUGC mode. Young Journalist. 2017. DOI: 10.15997/j.cnki.qnjz.2017.17.034

[4] Analysys. Annual comprehensive analysis of China's mobile audio market in 2018. [Online] 2018, Retrieved on April 5, 2021, from: http://www.199it.com/archives/720728.html

[5] Rui, H. Ear economy - mobile audio industry in-depth research report. [Online] 2018. Retrieved on April 5, 2021, from https://36kr.com/p/1722737393665

[6] Zhao, Y.Y. Ximalaya users exceed 600 million. [Online]. 2019. Retrieved on April 4, 2021, from: https://baike.baidu.com/reference/7379729/0a33U BeVLmEiD3H1Ldc4ah_tnV_nY3_M4gAFv5V3FUWyb9bExa64YYU51L16Mk0 AHz-UyRTxGbI23h4XOBKXgirRCD7K501xn5sdo

[7] Lai, L.J.; Zhang, H.X ASMR: A new location for the integration of audio platforms, users, and content - Based on user survey on the three platforms of "Ximalaya FM", "Litchi" and "Dingting FM". China Radio, 2020.

[8] A. Twin, The 4 Ps 2021. [Online] Retrived on April 4, 2021, from

https://www.investopedia.com/terms/f/four-ps.asp

[9] P. Yuanmeng, Ximalayan FM Marketing Strategy Research 2018. DOI: 10.27420/d.cnki.gxsyc. 2018.000158

[10] Sohu. Ximalayan FM Product Analysis Report. [Online]. 2019. Retrieved on April,4, 2021, from https://www.sohu.com/a/303909918_820218

[11] Liu, J. Research on mobile audio app "Ximalaya FM". 2019.

[12] Yang, Y.B.L.; Shen, G.Q. The concept of "PUGC" may open a new era in the webcast industry. [Online] 2016. Retrieved on April 4, 2021, from: http://game.people.com.cn/n1/2016/0504/c21005328324610.html 
[13] Zhao, S.L. A Research on the Business Model of Mobile Radio from the Perspective of Value Chain: Taking Ximalaya FM as an Example. New Media Research. 2018. DOI: 2096-0360(2018)10-0055-02

[14] Ximalaya University. Ximalaya FM University | New Anchor Training Camp. [Online] 2020. Retrieved on April 4, 2021, from: https://m.ximalaya.com/jiaoyupeixun/29314108/

[15] Data bar. Online audio platform creates a diversified profit model, and Ximalaya FM leads the market. [Online] 2019. Retrieved on April 5,2021,from: https://baijiahao.baidu.com/s?id=16272253413690 $77738 \& w f r=$ spider $\&$ for $=$ pc:

[16] Ao, Y.Q. Analysis of the profit model and profit strategy of "Ximalaya FM". New Media Research 2018. DOI: 2096-0360(2018)13-0042-02

[17] Zhao, S.L. A Research on the Business Model of Mobile Radio from the Perspective of Value Chain: Taking Ximalaya FM as an Example. New Media Research 2018. DOI: 2096-0360(2018)10-0055-02

[18] Chinese News. Didi Driving and Ximalaya FM achieve strategic cooperation and upgrade the layout of the industrial ecological chain. [Online] 2015. Retrieved on April 5, 2021, from: http://www.cankaoxiaoxi.com/science/20151209/1 021684.shtml

[19] Yangtz008. Ximalaya's financial data turned out to be like this. [Online] 2018. Retrieved April, 5, 2021, from:

http://www.360doc.com/content/18/0906/10/45163 544_784306133.shtml

[20] Q, Zhan, Analysis of the Development of China Mobile Audio Industry in 2020. The overall market size is nearly 9 billion yuan. [Online] 2020. Retrieved on April 12, 2021, from https://www.sohu.com/a/406242495_114835?_f=in dex_pagefocus_3\&_trans_=010001_grzy

[21] Baidu, User Generated Content (UGC). [Online] 2021. Retrieved on April,5, 2021, from https://baike.baidu.com/item/UGC/66502?fr=aladd in

[22] Q, Yue, Vice President, Litchi FM Products: UGC Product Experience Sharing. [Online] 2016. Retrieved on April,5, 2021, from http://www.woshipm.com/operate/444941.html

[23] Baidu, Professionally Generated Content (PGC). [Online] 2021. Retrieved on April 5, 2021, from https://baike.baidu.com/item/PGC/16859378?fr=al addin 